\title{
Discourse Analysis of Written Text on Pakistani Public Transport Vehicles
}

\author{
Rafia Bilal ${ }^{1} \&$ Wasima Shehzad ${ }^{2}$ \\ ${ }^{1}$ Department of English, Female Campus, International Islamic University, Islamabad, Pakistan. \\ ${ }^{2}$ Faculty of Social Sciences and Humanities, Air University, Islamabad, Pakistan \\ Correspondence: Rafia Bilal, Department of English, Female Campus, International Islamic University, \\ Islamabad, Pakistan. E-mail: rafia.bilal@iiu.edu.pk
}

$\begin{aligned} & \text { Received: December 10, } 2018 \quad \text { Accepted: January 8, } 2019 \text { Online Published: January 25, } 2019 \\ & \text { doi:10.5539/ijel.v9n1p496 }\end{aligned} \quad$ URL: https://doi.org/10.5539/ijel.v9n1p496

\begin{abstract}
This research focuses on the discourse analysis of the text written on Pakistani public transport vehicles. The data were collected from the roads, parking lots and market places in the twin cities of Rawalpindi and Islamabad. The text was written in three languages, English, Urdu and Punjabi. The sample size was fifty but in order to delimit the study, the data size was reduced to ten. The data classification was done keeping into consideration the grounded theory, as the thematic categories of data emerged after data collection. They included love for religion, parents, opposite sex and country. Moreover, it highlighted the theme of morality, socio-economic problems, desire for upward mobility and wisdom-based quotations. The data were then analyzed keeping in mind Janks' rubrics for linguistic analysis. The linguistic analysis showed that the text employs lexicalization, overlexicalization, lexical cohesion and there is extensive use of metaphors, euphemism and personification. It was noted that the text was multilingual as it was in Urdu, Punjabi and English language with a lot of code switching. The data were then further analyzed to highlight the social and moral attributes of language users, the socio-economic problems they face and their struggle for upward mobility. The social analysis provided a deep insight into the life of public transport drivers in Pakistani society.
\end{abstract}

Keywords: blue-collar working class, linguistic analysis, social analysis, vehicular discourse

\section{Introduction}

Discourse written on public transport vehicles is a very common phenomenon in Pakistan. One can find certain kind of written texts on many public transport vehicles while travelling on the roads throughout Pakistan. This text, on the vehicles, is written in various forms such as quotations, slogans, poetry, phrases and sometimes single words and images. The messages that this text conveys are wisdom based, religious, romantic and comic. Sometimes they highlight presence or absence of moral and ethical values or socio-economic problems. They also show one's love for religion, parents, beloved or love for the country. The political messages have also started to claim their space on the vehicles.

Elias (2012) in his book on truck art and the way they reflect the identity and culture of its drivers, mentioned that the first study that focused on truck art was conducted in the 1970's in Afghanistan, and after that numerous researchers throughout the world focused their attention on truck painting as a form of art. However, exploration of Afghan truck art came to an end in the same decade due to the Soviet invasion, followed by civil war in the country. At that time some Afghan refugees escaped to Pakistan and bought the tradition of truck art to Pakistan. Consequently, the study of Truck Art and decoration shifted from Afghanistan to Pakistan. Initially, truck art included decorative paintings (of beautiful landscapes, forests, animals like lions, birds like eagle and portraits of women) and artwork (mirror work, carving, woodwork etc.) on the trucks only, but with time, it evolved and also included written text. He further says that the decorative and attractive designs and patterns on the trucks signify a great deal about the religious, social and national identities of its drivers and owners, and one can observe a great deal of variation in the content written on the trucks and their decoration.

Gradually the tradition of writing on the trucks was adopted by the drivers of buses, Suzuki vans, carts and eventually, it became so common that it can be seen on cabs, private cars and motorbikes as well. The texts are written in Urdu, English, Punjabi, Pashto, Sindhi and other regional languages, throughout the country. 
Since the current research focuses on the discourse analysis of this text on the vehicles, it is important to define the term 'discourse'. Gee (2014) defines it as "Discourse is the sequence of sentences. It is the ways in which sentences connect and relate to each other across time in speech and writing" (p. 35). According to him, when a speaker speaks or a writer writes, he chooses a specific order to sequence his words and phrases. Discourse, therefore, relates to the way various sentences flow one after the other to create meaningful communication and to facilitate interpretation. Due to expansion and complex organization among the societies, and as a result of globalization, there has been observed sociolinguistic variation in the discourse of language users. This compelled the linguists to focus on the issues relating these variations and variational features of the languages and resulted in the study of the relationship between sociolinguistics and discourse analysis. Language is a mirror that reflects culture, social values, social attributes, moral and ethical values, religious attributes, socio-economic problems, desire for upward mobility and various other factors. Some of the researches that describe the relationship of language with different social variables have been discussed in the preceding paragraphs.

Crowell (2014) in his research article, comments that, "culture is a people's shared way of living". He classifies cultures as material and non-material culture. Material Cultures refers to the concrete objects that are created by people and they assign meanings to them, for instance, food, clothes, tools etc. Natural objects like rocks, water, stones, leaves, fruits etc. are not a part of material culture. On the other hand, non-material culture refers to abstract ideas and intangible entities (like laws, rules, customs, traditions and social roles etc.) They are shaped and mutually shared by each member of the speech community and they are transferred from one generation to the other. Crowell believes that all these material and non-material things are a guideline for the members of a culture to move in the society and interpret the world around him.

Costa et al., (2014) in their research article, "Your Morals depend on Language", has described how using a foreign language distances an individual from his own moral principles that he learnt while using his native language. He believes that if a person apprehends a moral dilemma, his response to resolve it should not depend on the fact that the dilemma is presented to him in native language or foreign language, but he has reported that people are prone to make thoroughly different judgments when they face a moral dilemma in a foreign language.

Ali (2010) in his research about militancy and socioeconomic problems in Pakistan has described various factors that have led to socioeconomic deterioration of the country. According to him, these factors include poverty, unemployment, illiteracy, corruption, poor health and educational facilities, lack of economic opportunities etc. He believes that improving socio-economic condition should be the top priority of the government, only then the living standard of the common man can be improved and the militant citizens would stop their volatile behavior and would start contributing positively towards the development of the country.

Younas et al., (2015) in their research, has used an interchangeable term to describe the same phenomena of 'upward mobility' and define it as: "Social mobility is such type of approach in which individuals, groups and families move from one social position to another to raise their social status within the society". According to them, sometimes it is just one individual and sometimes groups or families, who move from one social position to another, and the main purpose of this movement is occupation and education which ultimately results in upward social mobility. In order to study social mobility in their research, they selected two areas from Rawalpindi (city), named Dhouk Kala Khan and Christian Colony. The required data were collected randomly, through questionnaires and interviews, and secondary information was collected via articles, researches and internet. From this research, they came to know that a sizable number of people residing in Dhouk Kala Khan had migrated from different unprivileged areas including rural areas nearby. They had migrated due to their occupation, education, secure future of their children and for the sake of better life style. There were many young boys living with their friends, away from their families. The females living there were mostly illiterate but they had a positive attitude towards changing their social status. The people were economically not very sound. Very few of them were moderate and majority was quite poor. There were also some people who had socially mobilized in order to raise their social status by changing their career. In Christian colony, majority of the people were uneducated and they were even unable to understand the questions they were asked in the interview. In this area, people were economically more unstable as compared to Dhouk Kala Khan.

All these researches are evident of the fact that language is a mirror that reflects different social attributes of its users. The present research, by analyzing the discourse on Pakistani public transport vehicles, would also help in highlighting social variables that are attributed to blue collar working class of Pakistani society. 


\subsection{Statement of Problem}

These writings range from politics, informal advertising, threats, antidotes, jokes, religious texts, love poems and the list goes on. There are around six to ten million commercial vehicles, which include buses, trucks and three wheelers circulating on roads carrying the written text or visual art. There have been numerous interpretations of the artistry writings but none has been put to test to confirm the real purpose/meaning of the vibrant and seemingly arbitrary text on autos and trucks. In an effort to discover if this "art imitates life" an in-depth study is required. This research is carried out to understand the true meaning behind this flashy text and determine if these writings are used to address and deliver a message to an assumed community or only serve as eye candy for the sake of art. As research on Linguistics has been flourishing in Pakistan and expanding to various aspects of our day-to-day life, it is crucial to also study the textual art on the trucks and autos that is undisputedly an integral part of our cultural, but has long been overlooked and not given its due regard. As no substantial research work has been done from sociolinguistic perspective, i.e., analyzing the text linguistically and relating it with the social attributes, the current study has, therefore, bridged the gap in the field of discourse analysis and sociolinguistics in Pakistan.

\subsection{Research Objectives}

This research is based on the discourse analysis of the text from sociolinguistic perspective, therefore, the objectives of the current research have been categorized as the linguistic and social aspect of the research, and each aspect has its own objectives. They have been mentioned below:

\subsubsection{Linguistic Aspect}

The linguistic aspect of this research has the following objectives:

1) To find out the kind of lexical features that are employed in the text written on Pakistani public transport vehicles.

2) To verify if this text employs the use of linguistic features like euphemism, similes, metaphors and personification etc. and what is the significance of their use in this text?

3) To explore how different transitivity processes like material, mental, verbal, and relational, constitute the transitivity system of the language written on Pakistani vehicles.

\subsubsection{Social Aspect}

The social aspect of this research has the following objectives:

4) To explore the themes in the texts written on Pakistani vehicles.

5) To find out the driver's economic and financial condition.

6) To explore if this text reflects the driver's deprivation from basic necessities.

7) To understand how this text reflects the driver's desire for upward mobility.

8) To investigate the moral and ethical values and social attributes of the Pakistani society as reflected in the text.

\subsection{Research Questions}

Since the objectives of the present study have been categorized as linguistic and social aspect, therefore, the research questions have also been designed in alliance with the objectives. The research questions are:

\subsubsection{Linguistics Aspect}

The linguistic aspect of this research covers the following research questions:

1) What kind of lexical features are used in the texts written on public vehicles?

2) How does the text employ euphemism, similes, metaphors and personification in the texts written on public vehicles?

3) To what extent is transitivity a regular feature of the text written on pubic transport vehicles?

\subsubsection{Social Aspect}

The social aspect of this research covers the following research questions:

4) How does the text displayed on the public vehicles depict socio-economic status of the drivers?

5) Does the text written on the vehicles indicate the desire of the drivers for upwards mobility? 
6) To what extent does this text reflect the driver's deprivation from the basic necessities of life?

7) How does this text portray their moral and ethical values and social attributes of Pakistani society?

8) Does this text aim at rectifying social and economic problems of the country?

\section{Methodology}

The theoretical framework chosen for the current research is Halliday's Systemic Functional Grammar (1995). However, the analytical framework that has been chosen for this research is Janks' rubrics for linguistic analysis (2005). Janks derived this rubric from Halliday's Systemic Functional Grammar (1985) as it provides a basis for the linguistic analysis of texts. This rubric is quite comprehensive and encompasses a wide range of linguistic features. For current research Janks' model has been adapted and the following linguistic features have been selected for the analysis of vehicular discourse:

1) Lexicalization

2) Lexical cohesion

3) Metaphor

4) Euphemism

5) Transitivity

There are some linguistic features that are not a part of Janks' model but have been analyzed in the texts because they could not be ignored while analyzing the data linguistically. They include:

6) Similes

7) Personification

8) Bilingualism and multilingualism

\subsection{Data Collection}

The data were collected from market places and parking lots of different commercial areas in the twin cities, Rawalpindi and Islamabad. Some data were also collected while driving on the roads. There were two reasons for collecting data from Rawalpindi and Islamabad and the surrounding areas. First, I am a resident of Rawalpindi and work in Islamabad, and had easy access to the data from both the cities. Secondly, the text displayed on the public vehicles in these areas is usually in three languages Urdu, Punjabi and English and, as a sociolinguistic researcher, I am familiar with only these three languages, and not the other regional languages spoken in Pakistan.

\subsection{Sample Size}

In order to conduct the research, fifty samples of the text were snapshot but to delimit the study, the sample size was reduced to ten only.

\subsection{Sampling Technique and Data Classification}

The data were categorized keeping in consideration grounded theory. Grounded theory is a systematic methodology used in social sciences, and involves the construction of theory through the analysis of data. In this research, it began with the collection of qualitative data, which was then thoroughly reviewed again and again. As the repeated concepts and ideas became apparent, they were put into five categories.

1) Love (2 samples)

2) Morality (2 samples)

3) Socio-economic Problems (2 samples)

4) Upward Mobility (2 samples)

5) Wisdom Based Sayings (2 Samples)

The texts that were selected for the analysis were also translated into English and each translation has been given with the main text. In some texts, word-to-word translation was not possible, therefore, closest possible translation has been given. The translation was verified by two subject specialists, in order to make sure that it was representative of the source text. The purpose of providing the translation was that Urdu and Punjabi texts are not comprehendible for the English-speaking readers. 


\section{Data Analysis}

The analysis of the thematic categories of data, keeping in mind Janks' rubrics has been discussed below. At the end of linguistic analysis, social analysis of every text has also been done, in which the text has been discussed in relation to Pakistani society.

\subsection{Love}

Love is the most profound human emotion. It is a strong feeling of attachment for a person or a thing. Love can be divine, i.e., for Allah almighty (the creator). The study samples that encompass the theme of love have been analyzed below:

Table 1. Love

\begin{tabular}{ll}
\hline Main Text & Translation \\
\hline Chaand Mohammad (PBUH), Sitaaray Sahaba & $\begin{array}{l}\text { The driver has metaphorically called Prophet Mohammad } \\
\text { (PBUH) "moon" and his companions "stars" }\end{array}$ \\
\hline
\end{tabular}

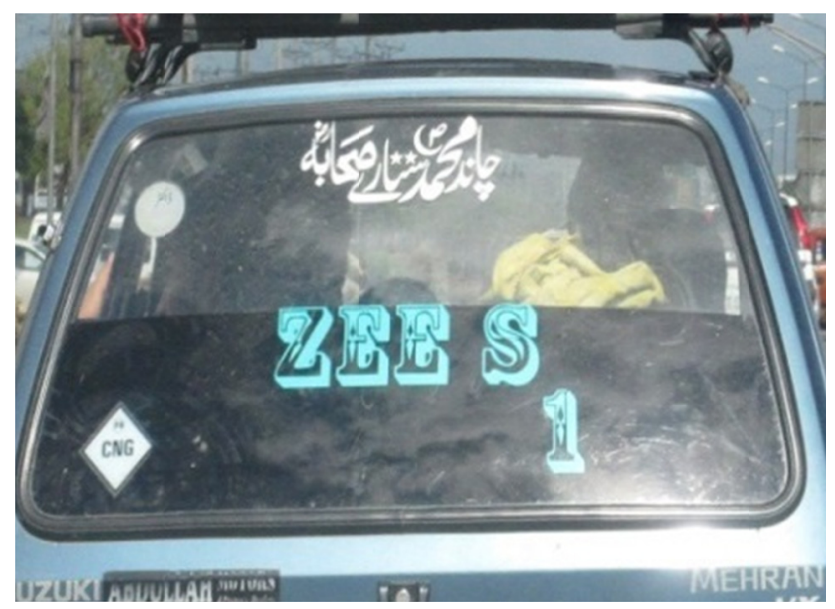

Figure 1. Love

Text 1:

Lexicalization

This text consists of a short phrase written in Urdu language.

The word "Sahaba" refers to the companions of Holy Prophet (PBUH).

The text shows driver's love for Holy Prophet (PBUH) and his companions.

\section{Lexical Cohesion}

The text is not cohesively linked, as the connectors and helping verbs are missing.

\section{Metaphor}

Two metaphors have been used by the driver in this text. He has called Prophet Mohammad (PBUH) "Chaand" which shows his significance and worth in the life of a Muslim. The way moon adds to the beauty of sky in the night, the same way Prophet Mohammad (PBUH) enlightened the world by his arrival, and spread the glory of Islam all over the world. In the same text, he has called Sahaba 'Sitaaray'. The way moon looks beautiful accompanied by innumerable stars, the same way Sahaba looked strikingly attractive and beautiful in the company of Prophet Mohammad (PBUH).

Through these metaphors, the driver has tried to express his immense love and devotion for the Holy Prophet (PBUH) and his companions.

Transitivity

The following transitivity processes have been observed in this text: 
a) Mental Process: Since the text expresses the driver's immense love for the Holy Prophet (PBUH), so it can be said that he is "sensor".

b) Verbal Process: Driver is the sayer, the people who read this text are the addressee, and verbiage is "Chaand Mohammad, Sitaaray Sahaba".

c) Relational Process: "Mohammad" and "Sahaba" are the carriers, and their attributes are that they are as beautiful as 'Chaand' (moon) and Sitaaray (Stars).

This text on the cab shows the driver's love and affection for the Holy Prophet (PBUH) and his companions. He wants to convey the message that the way he loves the Prophet (PBUH) and his companions, the same way every Muslim should love him and practically apply his teachings in everyday life. His life provides a complete code for living a successful life.

Table 2. Love

\begin{tabular}{ll}
\hline Main Text & Translation \\
\hline Sab kuch mila, waldain ki duaon say & Got everything because of parents' prayers. \\
\hline
\end{tabular}

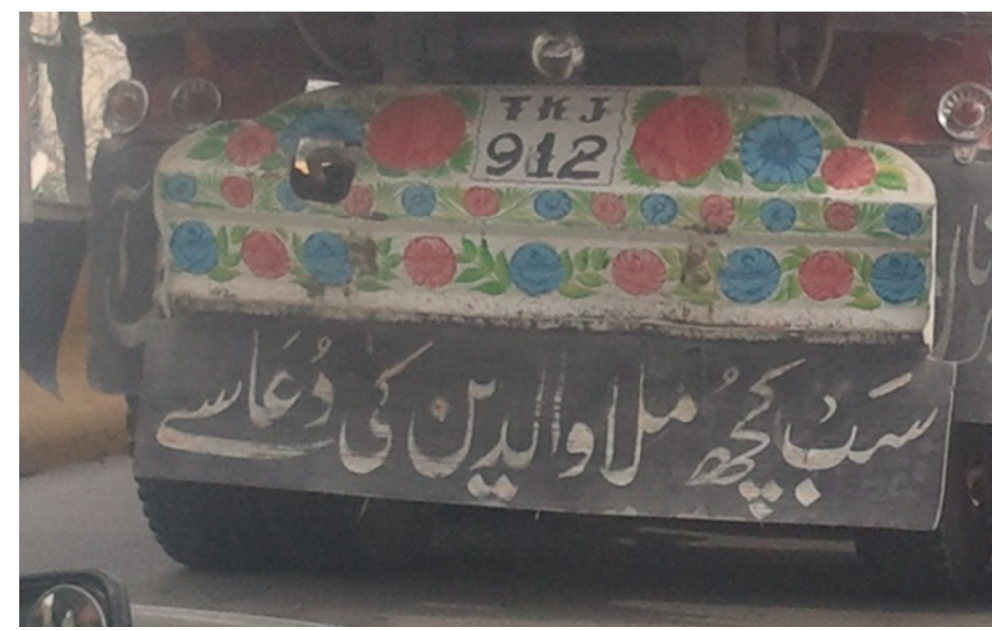

Figure 2. Love

\section{Text 2:}

\section{Lexicalization}

It is in Urdu language, and consists of a single sentence with two interdependent clauses. This text was also seen on many public transport vehicles including cabs, vans and rickshaws, and is one of the most commonly written texts on the vehicles in Pakistan. This text shows driver's love for his parents and he believes that whatever he owns is because of his parents' prayers. He feels that he is living a successful life only because his parents pray for him.

\section{Lexical Cohesion}

This text is lexically cohesive but seems inconsistent because it does not follow the syntactic structure of Urdu language.

Transitivity

The following transitivity processes can be observed in this text:

a) Material Process: The driver's parents are the "actors" who prayed for their son's success, while the driver himself is the "goal" who was positively affected by his parents' prayers. The driver, is also the "beneficiary" at the same time, because he is the one who has received a lot of blessings and worldly success as a result of his parents' prayers. 
b) Mental Process: It is also observed in this text. Driver is the "sensor" who believes in his parents' prayers for him. The phenomenon is, "sab kuch mila, waaldain ki duaon say". He acknowledges and appreciates his parents' prayers for him, which made him successful in his life.

c) Verbal Process: The driver is the "sayer", while every person who reads the text is the addresses, while the entire text is verbiage.

d) Relational Process: Driver is the "carrier", as he got everything, and "walidain ki duaon" is the positive "attribute" in this text.

This text expresses humble and down to earth nature of the driver, and his love and thankfulness towards his parents. It seems that he has been very obedient and respectful towards them and believes that whatever he possesses is because of his parents' prayers. The driver of this vehicle believes that his success is because of his parents' prayers.

\subsection{Morality}

It refers to knowing the difference between what is right and what is wrong. The texts that show the presence of moral values have been analyzed below:

Table 3. Morality

\begin{tabular}{ll}
\hline $\begin{array}{l}\text { Beemar khawateen — hazratt ko haspataal lay janay kay liay } \\
\text { yeh riksha bil-moawza dasteyab hay }\end{array}$ & $\begin{array}{l}\text { To transport the sick men and women to hospital, this rickshaw } \\
\text { is available for free. }\end{array}$ \\
\hline
\end{tabular}

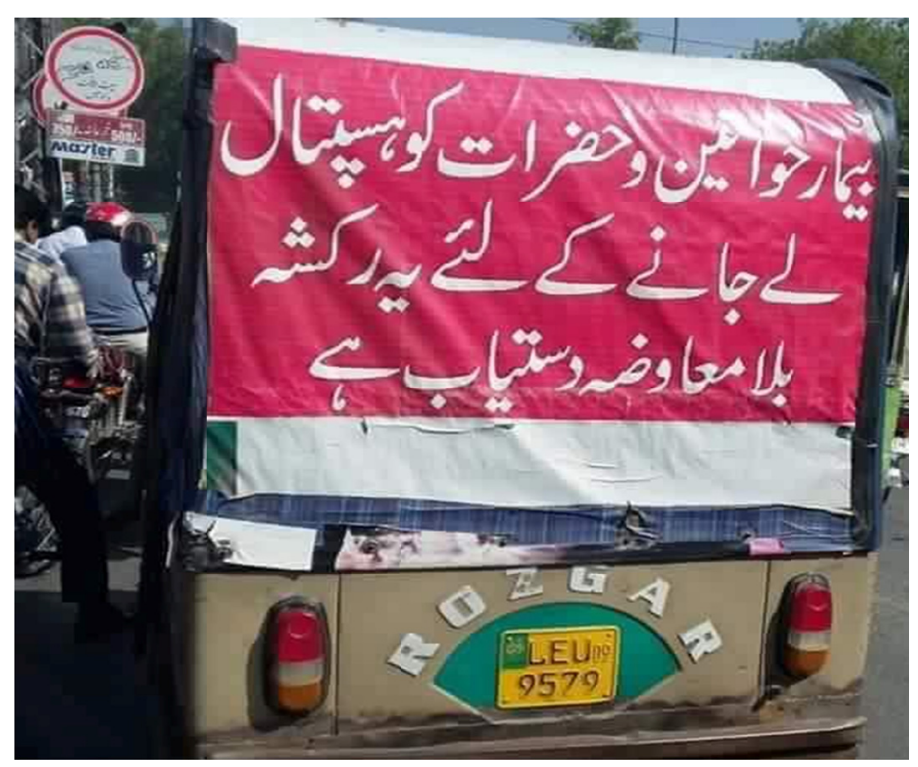

Figure 3. Morality

\section{Text 1:}

\section{Lexicalization}

This text is written at the back of a rickshaw. The whole text consists of one long sentence written in Urdu language. The driver has used very refined vocabulary and polite expression to convey his message. The choice of language shows that the driver wants to be read and understood by every person who reads the text, which states that this rickshaw driver is available to transport the patients to hospital free of cost. The text looks like an advertisement, but in fact it is simply an information which states the provision of social service for free for the poor and needy. The main theme of this text is driver's love for humanity and his spirit to be a helping hand for the needy people. 


\section{Lexical Cohesion}

Lexical cohesion can be observed in this text. The words "bila-muawza" and "khwateen-o-hazraat" are commonly used collocation in Urdu language. "Bila and moawza" and "khwateen-o-hazraat" often come together.

\section{Euphemism}

Euphemized words and expressions have been used by the driver, to convey his message in a politer manner. The word "khawateen-o-Hazrat" has been used instead of "logon" which is a neutral term, while khawateen-o-hazraat is a more respectable word. "Bilamuavza" is another euphemized or polite word in place of 'muft'. The word "muft" (free) seems impolite, but this rickshaw driver intends to serve the humanity for the sake of Allah's happiness, so he has used polite words and expressions.

\section{Transitivity}

The following transitivity processes have been identified in this text:

a) Material Process: In this text, the word "le jany" (taking) represents physical activity. "Yeh Rickshaw" is the actor, the word "haspatal" is the destination, and "bimaar khawateen-o-hazrat" are recipients as well as beneficiary.

b) Mental Process: Mental process can be seen in a way that the driver has sympathetic feelings for the people of his country. There is no sensor mentioned in the text directly but it can be perceived that the "driver" is the sensor while the word "bilamuawza dastayab" is the phenomenon of mental process.

c) Verbal Process: It is also observed in the text. Driver is the sayer, "beemar khawateen-o-harzaat" are the addresses, whereas "haspatal lay janay k liay yeh rickshaw bila-moawaza dasteyab hay" is the phenomenon.

d) Relational Process: The last part of the text "yeh rickshaw bilamuawza dastiyaab hai" shows the relational process. In the text "rickshaw" is the carrier and "dastiyaab" is the possession of this rickshaw.

Over-all this text highlights the driver's love for humanity and his high morals, who wants to fulfill the religious obligation to help and serve the poor and needy. He declares that he is ready to provide free transportation facility to the patients who want to use his rickshaw to reach the hospital. It can also be interpreted that he is inviting other people to be the part of this noble cause.

Table 4. Morality

\begin{tabular}{ll}
\hline Main Text & Translation \\
\hline Darwaza Please Holi Band Karen & Please Shut the Door Gently \\
\hline
\end{tabular}

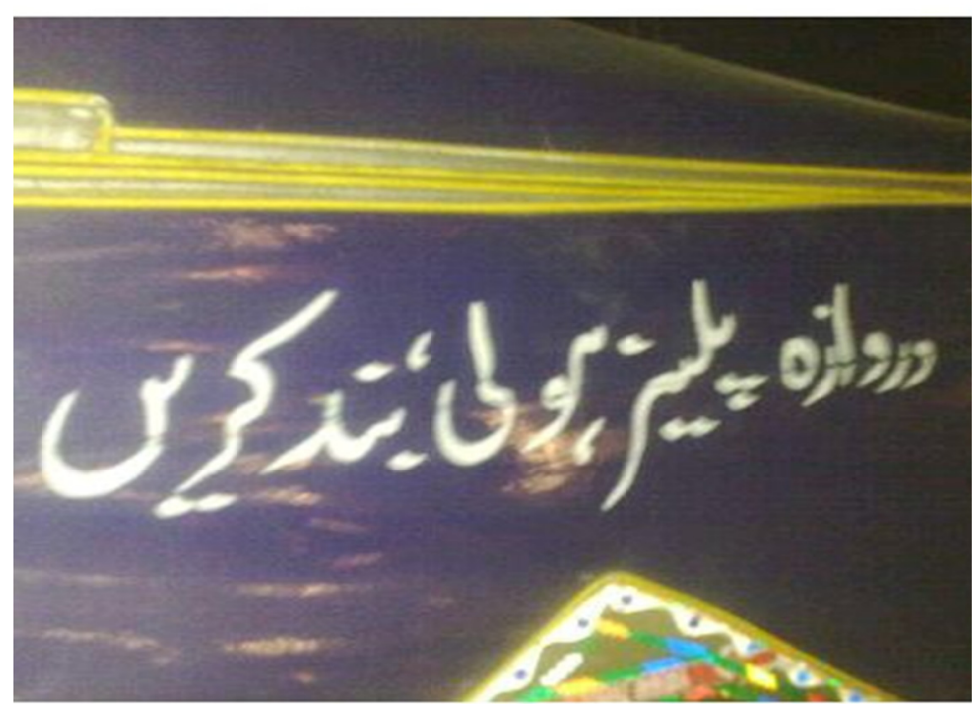

Figure 4. Morality 
Text 2:

\section{Lexicalization}

This text consists of a short sentence, written in Urdu language, but it contains an English and a Punjabi word also. The choice of Punjabi word "holi" (gently) shows driver's polite nature.

The driver has made a request to his passengers in a very respectful and humble manner.

\section{Lexical Cohesion}

The text is lexically cohesive, but the presence of a "comma" before the last two words makes it seem inappropriate.

\section{Euphemism}

The driver has used very polite words to make a request. Usually the drivers use impolite tone to convey such messages. Passengers shut the cab doors very noisily and it damages the car. The driver is requesting them to do it gently.

\section{Transitivity}

The following transitivity processes have been identified in this text:

a) Material Process: Passengers are the "actors" who shut the door, "door" is the goal, and "driver" is the beneficiary in this text.

b) Verbal Process: The driver is the sayer, passengers are the "addressees" and verbiage is "darwaza please holi band karen".

c) Relational Process: The passenger's negative attribute of shutting the door noisily has been discussed in this text.

The text indicates some of the moral and ethical values of Pakistani society. The people who travel in cabs, usually bang its door roughly. Not only this, it has also been observed that people take care of their own things and use them very carefully but when it comes to using other's things, they become very careless and rough. Same is the case with public transport.

It is a general observation that the public transport drivers are not polite in their manners and speech. They usually use slang or informal language, but this driver shows high moral values and good manners. The driver does not want his customers to leave his vehicle with an ill feeling so he has conveyed his message very politely.

The use of an English word in Urdu text shows the driver's desire for upward mobility, as command on English language is considered a gateway to success and upward mobility in Pakistan.

\subsection{Socio-Economic Problems}

The unavailability of three basic necessities i.e., food, clothing and shelter leads to socio-economic problems in any country. Social problems are interwoven with economic problems. When these problems are not timely met, they lead to bigger problems like corruption, poverty, inflation, unemployment, bribery and corruption etc.

Table 5. Socio-economic problems

\begin{tabular}{ll}
\hline Libaas hay muqaddam, to hifz-e-emataqaddam & Clothes are important but be-warned!!! \\
Baray patton walay darakht laga lo sahib & Grow big-leaved trees \\
Aanay wala budget awami choray ga na pant pajama & Because the up-coming budget will neither leave you \\
Phir band kay pattay meri jan, jheenga la la Pakistan & with clothes nor the under-garments \\
& And you will need leaves to cover your bodies \\
& Then you can dance like primitives. \\
\hline
\end{tabular}




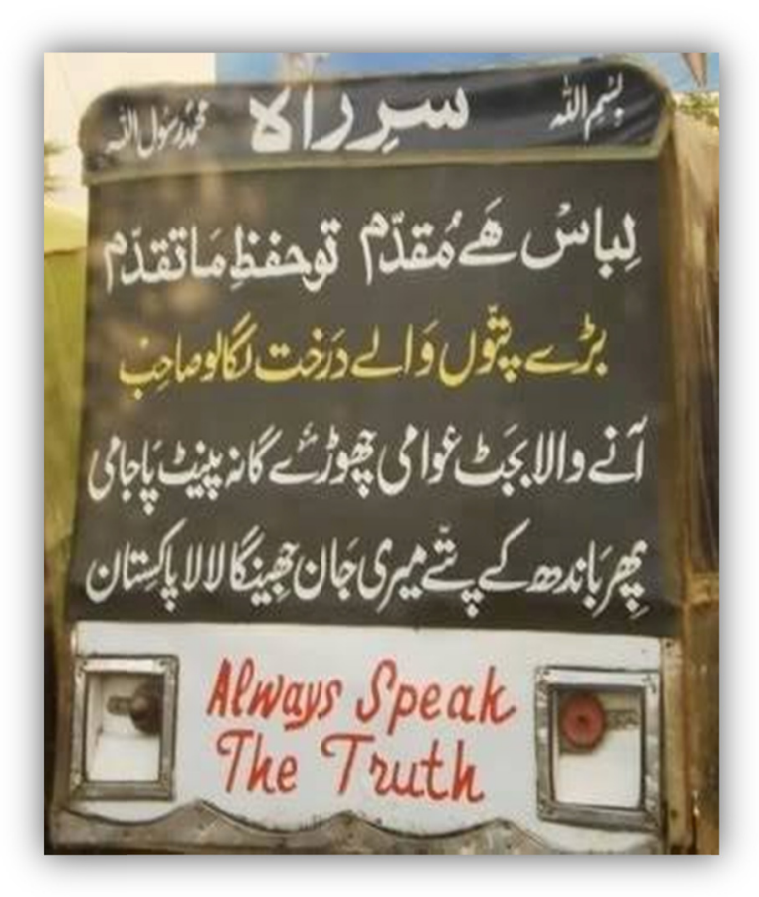

Figure 5. Social economic problems

\section{Text 1:}

\section{Lexicalization}

This text is written in Urdu language. It consists of four inter-connected sentences. Each sentence consists of two clauses, and the last words of two clauses in every sentence are in a rhyme scheme. In first sentence, rhyming words are: "muqaddam" and "hifz-e-mataqaddam". In third sentence, the words are "awami" and "pajami". In last sentence, the words are "jan" and "Pakistan".

This text highlights the theme of high rate of inflation and poverty and its effects on common man, after the budget 2016-17 would be announced.

The facts have been reported in a humorous way, but the underlying theme is quite serious and brain-wrecking for a common man. The choice of words shows witty nature of the driver.

\section{Over-lexicalization}

Over-lexicalization is evident in this text as the theme of inflation and rise in poverty rate has been explained using different ideas.

\section{Re-lexicalization}

Re-lexicalization can also be observed in the last sentence. The word "pajama" has been re-lexicalized as "pajama".

\section{Lexical Cohesion}

Lexical cohesion has been maintained in this text. It can be observed in the form of:

a) Synonyms: The words, "Pent" and "Pajaami" are synonymous words used in the third sentence.

b) Repetition: The word "pattay" (leaves) has been repeated in second and fourth sentence.

c) Collocation: The word, "hifz-e-mataqaddam" is a collocative expression used in the first sentence.

\section{Metaphor}

The driver has metaphorically said that after the announcement of new budget, poverty will increase and people will be bound to cover their bodies with leaves, instead of clothes. Through this text, the driver wants to convey the message that people already do not have enough money to feed their families properly even once a day, and the new budget will worsen their condition. 


\section{Transitivity}

The following transitivity features have been identified in this text:

a) Material Process: According to this text, government is the "actor" who is going to announce the budget, whereas the Pakistani citizens are the "goal" who are going to be negatively affected by this action. They will wear leaves instead of clothes, due to high rate of inflation.

b) Mental Process: The text expresses the driver's perception that after the announcement of bugdet, people will tie leaves on their bodies to cover their private body parts and go back to the primitive times. The driver is, therefore, the sensor.

c) Verbal Process: The driver is the "sayer", all Pakistani nationals especially the people who are living below poverty line are the "addressees", while the entire text constitutes "verbiage".

d) Relational Process: The coming budget is the 'carrier' which is being described in this text. And its negative attribute is that it will snatch the right from the people to afford buying clothes for themselves.

e) Behavioural Process: The text is expressing driver's witty nature and his compromising attitude. He is prepared to face the alarming increase in poverty rate and he wants his fellow men also to be mentally prepared for it.

Bilingualism

The text contains only one English word, "pant", which makes it bilingual.

On the whole, this text portrays the foreseen situation of a poor man after the announcement of financial budget every year. The driver of this rickshaw seems to be a witty man, who seems to be contented with his fate. Though he is drawing the attention of readers towards a very serious issue, but he has explained in a humorous manner. Through this text, he wants to mentally prepare his fellow nationals that they should be ready to face the rise in inflation and poverty rate. A common man is unable to meet the basic necessities of life already, but after the upcoming budget would be announced, people would grow so poor that thy will not be able to afford to buy clothes for themselves. He is telling the people to grow trees that have large sized leaves, and they can use those leaves to cover their bodies. Actually, he is trying to say that our country is, instead of developing, going back to primitiveness and Stone Age.

Table 6. Socio-economic problems

\begin{tabular}{ll}
\hline Main Text & Translation \\
\hline Pyar tay karan, par tankhwah bari thori ay & I would rather love, but meagre salary does not allow. \\
\hline
\end{tabular}

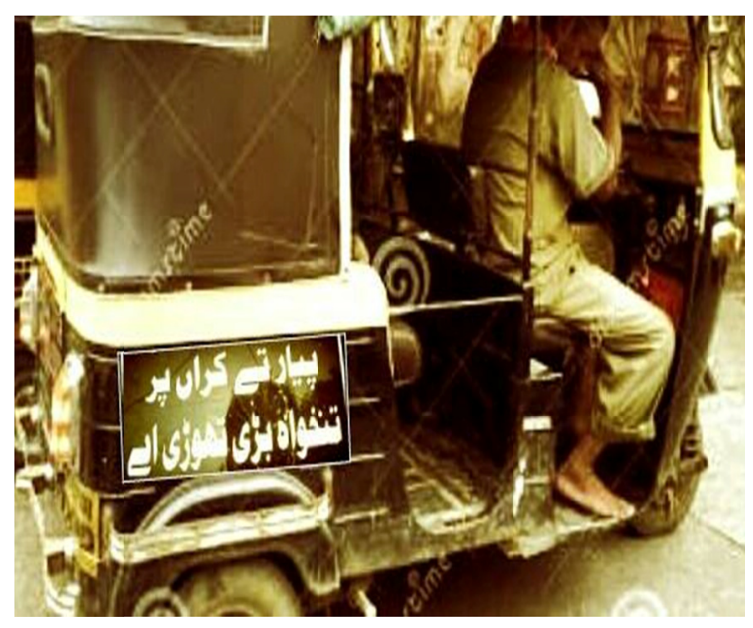

Figure 6. Socio-economic problems 
Text 2:

\section{Lexicalization}

This text is written on a rickshaw. It consists of a single sentence in Punjabi language, comprising of two clauses. The statement depicts the poor financial condition of the driver. He is unable to get married and show his love to his beloved because of his meagre salary. He is highlighting the fact that love sustains in a relationship only when necessities can be met.

\section{Lexical Cohesion}

Lexical cohesion has been observed in the text. A pair of antonyms, "bari" (a lot) and "thori" (less, meagre) has been found.

\section{Euphemism}

The text expresses a bitter reality prevalent in our society. In an indirect manner, the driver is saying that even "love" is not available for free. Just like all other relations, love also has lost its purity and sacrificing trait in today's materialistic society. Secondly, it has become demanding, expensive and selfish in a way that people do not accept marriage proposals from the suitors who are not upto their financial standards. No one considers the piety, righteousness, and other good qualities because it is the financial status that overweighs in majority of the cases. The writer is not directly saying that love is inflated, instead he is taking the blame on his own self and saying that his salary is not up to the mark.

\section{Transitivity}

The following transitivity features have been observed in this text:

a) Mental Process: This text shows the observation of the driver on the basis of the experience of others, and it is also a common perception in Pakistani society nowadays that love sustains only when the material needs are timely met. The driver is the sensor, as he says, "pyar tay karan" and the remaining part of the text describes the phenomenon "par tankhawa bari thori ay".

b) Verbal Process: The driver is the sayer, his beloved and everyone else who reads the text is the addressee, whereas the entire text is verbiage.

c) Relational Process: Relational process can also be observed in this text. "tankhwa" (income) is the carrier, "bari thori" is the attribute and "hai" is the process.

First glance at the text makes the readers feel that the writer is talking about his love life and beloved but the second sentence makes it clear for the reader that the driver is highlighting his socio-economic condition. It states that his salary does not allow him to engage in matrimonial relationship. The driver is confessing that he does love his beloved but he cannot afford to legalize his love in a respectable relationship because his income is meagre and he is incapable of affording the domestic responsibilities. Another fact which is highlighted here is that the sacrificing nature of love that could be seen in the previous times cannot be found now. Love has also become selfish, impure and materialistic.

Through this text, the driver has tried to bring a harsh reality to limelight. The piety, righteousness, faithfulness and loyalty are the qualities which are rare nowadays, but are usually neglected if the suitor is financially unstable. This gives rise to illicit love affairs and has become a very common practice among youth, thus resulting in moral degradation of Pakistani society.

\subsection{Desire for Upward Mobility}

The term upward mobility refers to the struggle for improving socio-economic status by getting education, switching job or marriage etc. In Pakistan, being fluent in English language is a license for upward mobility.

Table 7. Upward mobility

\begin{tabular}{ll}
\hline Main text & Translation \\
\hline Main bara ho kar truck banun ga & When I grow up, I will be a truck \\
\hline
\end{tabular}




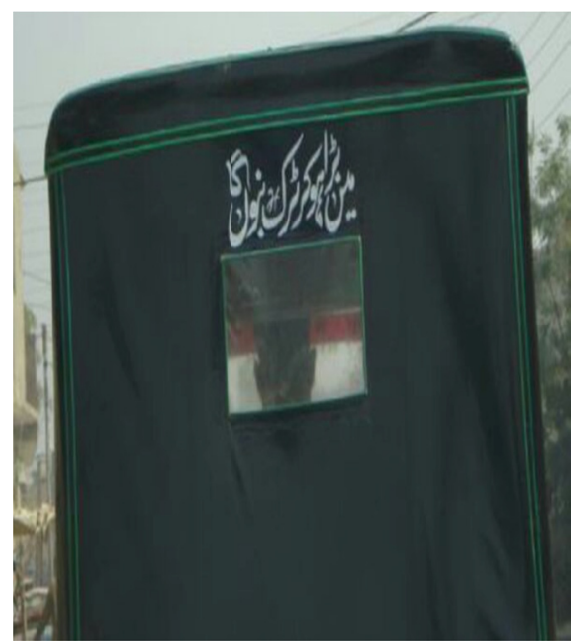

Figure 7. Upward mobility

\section{Text 1:}

\section{Lexicalization}

This is a quite short text consisting of a sentence, written at the back of a rickshaw. The text is written in Urdu language, however an English word "truck" has also been used but it is written in Urdu transcript.

The text shows the driver's optimism and hope to have a better future in the days to come. Currently the driver owns a rickshaw and becoming a truck driver shows his desire for upward mobility.

\section{Lexical Cohesion}

The words are interwoven in the text correctly. They are related to one another and together make the meaning of the text prominent.

\section{Metaphor}

The word "truck" has been used metaphorically to express the driver's desire to own a truck. He has expressed his desire in an indirect but comic way. He is saying metaphorically on the behalf of his rickshaw that it will turn into a truck when it grows bigger. It refers to the driver's intention to earn and save through his rickshaw and later on when he has enough savings, he would buy a truck and become a truck-driver. Being a truck driver would have better prospects for him in his life.

\section{Personification}

The words, "bara ho kar" and "banun ga" are the human attributes mentioned in the text and they refer to driver's intention to keep saving his money until he becomes economically stable and capable of buying a truck.

\section{Euphemism}

This short text highlights the hope and desire of the driver for a better and prosperous future. The linguistic feature of euphemism can be found in the text as the writer has used "main bara ho kar truck banoun ga". He could have said in a complaining manner that his vehicle is small and he is economically unstable, but he has expressed his desire in an optimistic way and is hoping to get his vehicle exchanged with a truck.

\section{Transitivity}

The following linguistic features of transitivity have been identified:

a) Mental Process: Mental process can be seen in the text as the writer is showing his affection for his profession and vehicle and wants to prosper in the same profession in his future. In the text "main" is the sensor and "bara ho kar truck" is the phenomenon.

b) Verbal Process: The text can be taken as a verbal process as the writer is telling the readers his future plans. "Main" is the sayer ("main" refers to rikshaw, and the driver is talking as if it is his rikshaw that is communicating with the audience), addressee is not directly mentioned but it seems that every reader who reads the text is addressee and "bara ho kar truck banoun ga" is the verbiage. 
c) Relational Process: This process can also be observed in the text as the driver, on the behalf of rickshaw has mentioned of becoming a truck after he grows bigger. "Main" is the carrier, "truck" is the attribute and "banoun ga" is the process.

Bilingualism

The text is written in Urdu language but there is one English word "truck" written in Urdu script.

On the whole, this text represents the driver's desire for upward mobility. His choice of words shows that he is very optimistic and determined to work hard for a better future. The text seems to be a comic one but in fact it carries a deep message. On a lighter note, it is reflecting the struggle of the people who face economic constraints and keep desiring and working hard for an economically sound future. In future this rickshaw driver wants to see himself as a truck driver, which means he wants to excel in his current profession as a driver.

Table 8. Upward mobility

\begin{tabular}{ll}
\hline Main Text & Translation \\
\hline Aaj kal ki larkian husn pay naaz karti han, pehla kalma & $\begin{array}{l}\text { Girls, nowadays are very much beauty conscious. They do not know } \\
\text { aata nahi English main baat karti han }\end{array}$ \\
the basics of religion but they take pride in communicating in English. \\
\hline
\end{tabular}

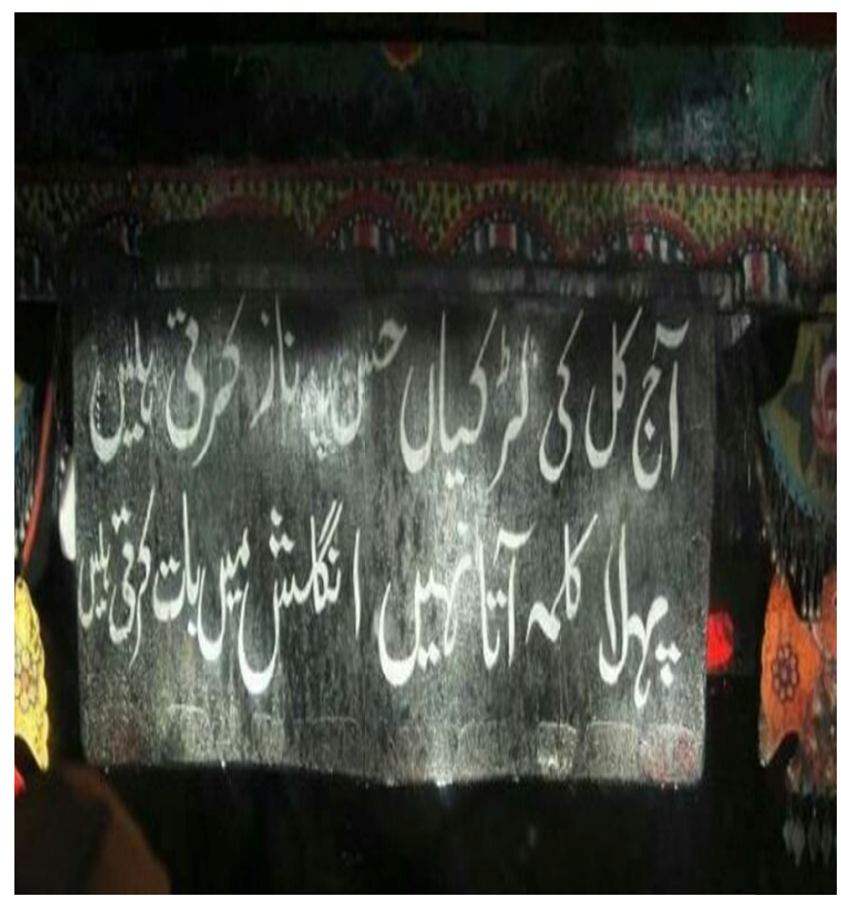

Figure 8. Upward mobility

\section{Text 2:}

\section{Lexicalization}

This text is written at the back of a truck and comprises of two sentences written in poetic form, i.e., in two lines. The first line consists of a complete sentence, and second line consists of two interdependent clauses. The choice of language for the entire text is Urdu, however, the driver has used an English word "English". The writer could use the word "angrezi" which is an Urdu substitute for the word "English", but his selection of an English word in Urdu text shows his awareness that English is considered to be a prestigious language.

Through this text, the driver is highlighting the fact that girls nowadays are obsessed with their physical beauty, and they tend to communicate more in English language. Unfortunately, they are unaware of Islamic teachings and they have engaged themselves so much in worldly affairs. They only know the importance of beautifying themselves and interacting in English language (as, both the factors, highlighting and enhancing their physical beauty and interacting in English contributes to their becoming superior as compared to others, in current 
Pakistani society) but they do not know the importance of religious teachings, and for this reason they are far from religion.

\section{Over-lexicalization}

Over-lexicalization has been identified in this text in a way that the driver has used many words to describe the fact that girls in Pakistani society are deviant from their religion. The words, "husn pay naaz karti han", "pehla klama aata nahi" and "angrezi main baat karti han", show their deviance from Islam.

\section{Lexical Cohesion}

Lexical cohesion can be observed in the text. All the words are lexically cohesive. Repetition can be observed at the end of both the poetic lines, as, the words "karti han" have been repeated.

\section{Euphemism}

Euphemism can be perceived in the text as the writer is portraying the harsh reality of current Pakistani society in a slightly humored manner. The driver believes that the girls take pride in displaying their beauty and do not cover themselves as per Islamic principles. They have become status conscious and to express their superiority over other people, they choose English to interact. Urdu is the national language but people, especially girls feel honored to converse in English. Instead of promoting our own language Urdu, they feel appreciated to be fluent in English language. (This paragraph has been revised and a sentence has also been omitted).

The second line of the text is stating the fact that girls nowadays have kept themselves distant from their religion and they are not familiar with Islamic teaching. "pehla kalma aata nahi" is a very harsh comment but in fact it implies that they do not practice Islamic teachings.

The whole text is highlighting negative aspects of the Pakistani society, i.e., how girls are brought up these days, but the writer has efficiently used a witty manner to portray this reality.

\section{Metaphor}

The word "kalma" has been used metaphorically in this text. This word "kalma" is the representative of the religion "Islam" and encompasses all the Islamic teachings that promote an Islamic life style. When the driver says that "kalma aata nahi", he is implying that girls are not aware of religious teachings and even if they do, they do not practically follow its teachings in their daily life. They call themselves Muslims, but their life style does not match with their religion. They have westernised themselves and are proud of it.

Transitivity

The following transitivity features have been identified in this text:

1) Material Process: In the second line of the text, "angrezi main baat karti han" is a material process. "larkiyan" (girls) is the actor, "angrezi" is the goal, and "baat karti" is process.

2) Mental Process: The above text can be taken as mental process of the girls. "Larkian" are sensor, "husn par naaz karti han" is the phenomenon that they experience. They feel pride in their physical beauty. "pehla kalma aata nahi" is also a phenomenon in second line of the text, which shows they are distant from their religion.

As the driver is expressing his observations that he has witnessed in the society, he is also acting as the "sensor" and "pahla kalma ata nahi English main baat karti hain" is the phenomenon of this text.

3) Verbal Process: This text can be taken as verbal process as the writer is sharing one of the negativities currently prevailing in Pakistani society. The text does not directly employ the words like "say or tell". It can be said that writer is the "sayer", everyone who reads the text is "addressee" and the entire text, "aaj kal ki larkian husn pay naaz karti han, pahla kalma ata nahi, English main baat karti hain" is the verbiage.

4) Relational Process: The writer is mentioning negative attributes of the present generation of girls, so relational process is evident here. In the text, "larkiyan" is the carrier, "husn pe naaz karti han" is the attribute and "karti hain" is the process. In the second line of the text, "angrezi main baat karti han" is another attribute. "karti han" at the end of both the lines shows "process" that is undertaken on regular basis.

"Angrezi main baat karti" and "husn pay naaz karti" can be taken as "tokens", as the two attributes equate each other and they come in contrast with Islamic teachings.

\section{Bilingualism}

The text is written in Urdu language, but the presence of one word "English" makes it bilingual. It is regular feature of Pakistani text that it employs English words in Urdu text. 
On the whole, this text is emphasizing the present state of the religion in our society. The driver has targeted only female young citizens of Pakistan and mentioned that they are more prone to indulge in fashion and exposing their physical beauty and they take pride in doing this. Moreover, they also communicate in English which shows their status consciousness. The girls are so much obsessed with English language that they have set it as the criteria to be known as "knowledgeable". But when it comes to Islamic teachings, they do not know even the essentials. And, even if they do know, they feel hesitant to practice it as they assume it as a hindrance in their way to upward progression.

Though the text has targeted young females only, but above-mentioned facts are equally applicable to the whole nation, including males as well as females. They have become the victims of moral and religious degradation. They are acquiring worldly education and love to show themselves as a modern and progressive nation, but they have gone far from their religious roots and have deviated from Islamic code of life.

The above analysis depicts the drivers as well as girls' desire for upward mobility. Being fluent in English language is a license for upward mobility in Pakistan. The next section discusses the wisdom-based texts, written on public transport vehicles in Pakistan.

\subsection{Wisdom-Based Quotations}

Table 9. Quotations

\begin{tabular}{ll}
\hline Main Text & Translation \\
\hline Jab tak zar lutao gay zair-dast hay dunya zara sa & $\begin{array}{l}\text { As long as you keep spending money on people, or keep benefiting } \\
\text { them, they respect you. Try withholding and you will find out how } \\
\text { opportunists they are. }\end{array}$ \\
\hline
\end{tabular}

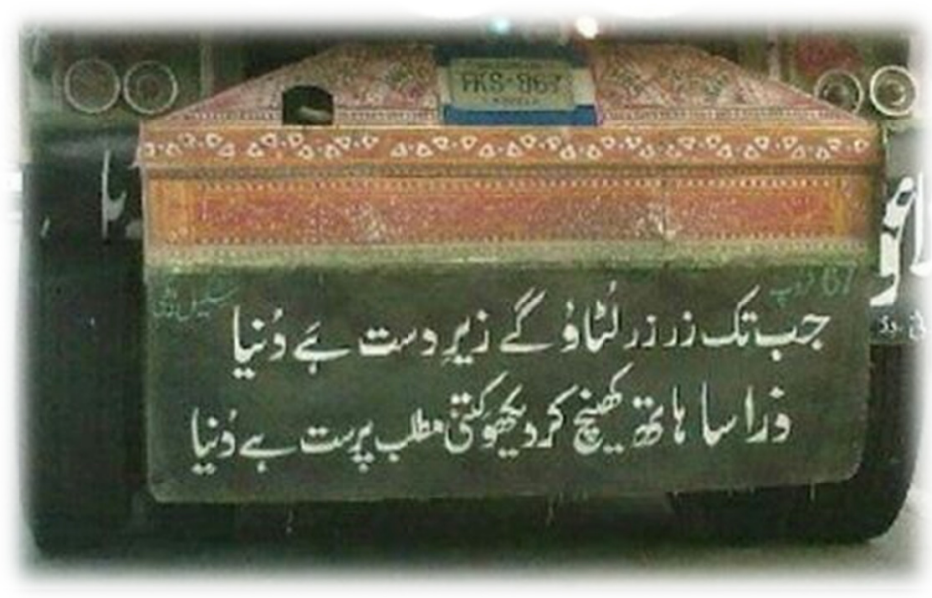

Figure 9. Quotation

Text 1:

\section{Lexicalization}

This text is a poetic verse in Urdu, consisting of two lines. The selection of language shows the strong affiliation with the national language of Pakistan.

Through this text, the driver is emphasizing the selfish nature of people nowadays and states that people are good to you as long as you are beneficial for them but once you are unable to do anything for them, they immediately turn selfish.

\section{Over-lexicalization}

Over-lexicalization can be observed in this text, as the driver is portraying the selfish nature of people by giving an elaboration. The words, "lutao gay", "zair dast, hath kheench" and "matlab parast" are contributing to the main theme of the text. The reader can analyse with the help of these words that what the writer is trying to say.

\section{Lexical Cohesion}

This text is lexically cohesive. It can be observed in terms of: 
a) Repetition: The two words at the end of both the lines of verse show repetition of the same words, i.e., "hai dunia". The repetition of word "zar zar" implicates spending money lavishly.

Antonyms have also been used in the text. They are, "lutao gay" (to spend) and "hath kheench" (stop spending). "zair dast" (submissive) and "matlab parast" (selfish and mean) are also words opposite to each other in meaning.

b) Collocation: Two collocations have also been used in this text. They are "Zair dast" and "matlab parast". These words convey different meanings when they are taken in isolation, but when they co-occur and they take different meanings.

Metaphor

The word, "dunya" has been used metaphorically to refer to the people nowadays.

Transitivity

The following transitivity features have been identified in this text:

a) Material Process: Material process is found in the text. Although, there is no actor directly mentioned in the text, but who so ever spends lavishly on others is the actor, while "zair dast and matlab-parast dunya" is the beneficiary.

b) Mental Process: The text shows the mental process. The words like "zair-dast" and "matlab-parast dunya" is the phenomenon while "the driver" is the sensor.

c) Verbal Process: This process is also involved in this text. The driver is sharing a bitter reality of the people nowadays. Therefore, driver is the sayer, everyone who reads the text is the addressee, while the entire text "jab tak zar zar lutao gay zair-dast hay dunya, zara sa haath khainch kar dekho kitni matlab parast hay dunya" is verbiage.

d) Relational Process: Since the text is mentioning the negative attributes of dunya (or people). In the first line, the word "zair dast" is the attribute while "dunia" (people) is the carrier and "hai" is the process. While in the second line, "matlab parast" is the negative attribute, "dunia" is the carrier and "hai" is the process.

The text is portraying another harsh reality of Pakistani society in today's era. People are not sincere to each other. And those who are sincere and loyal to others, people use them for their worldly benefits and once they are unable to financially support them or benefit them in any other way, they are betrayed and left alone. Unfortunately, this is a very common practice among people and definitely noticeable everywhere. Humanity is diminishing day by day and it is getting difficult to trace morality among people.

Table 10. Quotations

\begin{tabular}{ll}
\hline Main Text & Translation \\
\hline Surat buri, na seerat buri. Bura who jiski niyyat buri & $\begin{array}{l}\text { Bad is not a person who looks bad. } \\
\text { Bad is the one whose intentions are bad. }\end{array}$ \\
\hline
\end{tabular}

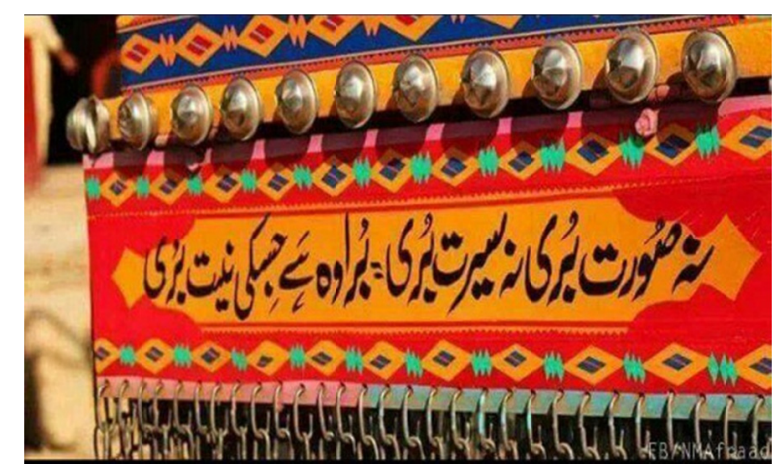

Figure 10. Quotation 
Text 2:

\section{Lexicalization}

The text is written at the back of a truck. It is written in Urdu language. The text is written in two sentences which are in verse form. The text states that neither it is the face which is bad nor the nature, rather bad person is the one who has bad intentions.

The writer has chosen the words carefully to give his message cautiously to the readers that they should not hold bad intentions for others.

Lexical Cohesion

The text is lexically connected. The word "hai" is connecting the whole text.

Euphemism

The whole text is an example of Euphemism. The writer is sharing his own unpleasant experience in a polite manner and is advising people not to have bad intentions for others, so that no one else should feel bad like he did.

\section{Transitivity}

The following transitivity processes have been observed in this text:

a) Material Process: The sentence "bura wo hai jiski niyat buri" shows the material process. "Wo" is the actor "niyat" is the process and "jiski" is the goal. (Last sentence from this line has been deleted).

b) Relational Process: The writer is giving attribute to the people or readers which makes it a relational process. The sentence "bura wo jiki niyat buri" shows the relational process. "Niyat" is the carrier, "buri" and "bura" is the attribute and possessor is the one who has bad intentions.

This text is written in Urdu language. The writer is talking about the nature of human beings. He says it is not the nature and the looks that are unattractive but the intentions which categorize a person as bad or good. So one should not be worried about his looks but should work on beautifying his/her inner self. If every person starts thinking this way then there would be no hatred. Bad intention here refers to the ugliness of the inner self. If one can control his intentions then he can control everything. (two words, and a sentence has been deleted from this paragraph)

\section{Discussion}

After the analysis of data, it was concluded that the drivers have used emotive language in the texts written on their vehicles. Emotive language is the one that helps to involve the readers and makes them feel in a particular way. It creates an emotional response from the reader (e.g., patriotism, excitement, optimism, pity, guilt etc.) and can create a positive or negative effect on their minds. It was also observed that these data are rich in a way that it employs a lot of linguistic features making it interesting for the readers to grab their attention.). Moreover, this research highlights the major traits and features of Pakistani society in a number of ways.

The lexical features that were focused upon during the analysis of data included lexicalization, over lexicalization, re-lexicalization and lexical cohesion. Lexicalization refers to the selection or choice of words. It was found that the majority of texts were in Urdu language and there was only one text that employed the use of Punjabi language. However, use of a few English words was observed in Urdu and Punjabi texts. Most of the texts were short consisting of single sentences. Two texts were in the form of poetic verses. There was only one text that was considerably large, consisting of five lines and employed the use of rhyming words, "muqaddam and ma-taqaddam" and "awami and pajami". The second lexical feature that was studied in the texts was over-lexicalization. Since most of the texts were quite short, it has been found in only three texts. It was most evident in the text where the richshaw driver was mentally preparing the readers about the upcoming budget. Re-lexicalization was the third lexical feature that could be found in only one text on only one vehicle, written on a rickshaw. It was a long text and in order to create a rhymes scheme in alliance with the preceding phrase, the word "pajamas" was re-lexicalized as "pajami", which is not used otherwise in spoken or written language. Therefore, it can be said that re-lexicalization was not very much apparent in the text on public vehicles. The next lexical feature that has been analyzed is lexical cohesion which has been noticed to be existent in almost all the texts on the Pakistani public transport vehicles. Almost all the texts were lexically cohesive with an exception of the first text.

The use of metaphors and personification was evident in the texts. Their use helps to create a visual image in the minds of the readers. For instance, in a religious text, "Chaand Mohammad, Sitaray Sahaba" the word "Chaand" 
(moon) has been used metaphorically to show the glory, splendor and magnificence of the Prophet Mohammad (PBUH). The way the moon exalts the beauty of a night, the same way, Prophet Mohammad's (PBUH) arrival glorified the world and bought peace, harmony, love and brotherhood among mankind through his Islamic teachings. Personification has been observed in the text that says, "main bara ho kar truck banun ga". The words, "bara ho kar" and "banun ga" are the human attributes mentioned in the text and they refer to driver's intention to keep saving his money until he becomes economically stable and capable of buying a truck. The same text shows the use of euphemized expressions. The driver could have said in a complaining manner that his vehicle is small due to his meagre earning but he stated it in an optimistic manner.

From the current research, it was concluded that transitivity is the most common feature of linguistic analysis. All the texts that were selected for analysis, showed different transitivity processes, including material, mental, verbal and relational processes. From this research, it was concluded that all these processes constitute the transitivity system of language, which belongs to the experiential metafunction. So, it can be said that transitivity analysis describes how language interprets our experience of the world around us.

An important feature of these texts written on public transport vehicles was bilingualism and multilingualism. Urdu texts employ English words, usually written in Urdu transcript. Similarly, Punjabi texts use English words written in Punjabi transcript. There was one text, "darwaza please holi band karen" that was in Urdu language and had one Punjabi and one English word, making the whole text multilingual. Being fluent or well-versed in English language is considered a gateway to success in Pakistan, therefore, the use of English words in the text shows the desire of drivers for upward mobility in an indirect manner.

The conclusive findings of my research manifest the fact that the text written on Pakistani public transport vehicles evidences the use of almost all linguistic features. There is careful selection of words, choice of language and each text carries a specific message for the readers. There is use of metaphors and personification to create visual images in the minds of readers. Many drivers have used euphemized expressions to state unpleasant things in a polite manner. The finding of my study show that vehicular discourse is a complete and new genre of study in the field of linguistics in a way that it has not been previously studied or analyzed linguistically in Pakistan. Janks (2005) model has been comprehensive and reasonably supportive in analyzing the text in my research in linguistic terms, as it employs all the important linguistic features that can be taken into account to understand and analyze any linguistic text. Moreover, this text highlighted driver's love for religion and parents and some of their high morals. It also highlighted some of the socio-economic problems and the drivers' desire for upward mobility.

\section{References}

Ali, A. (2010). Militancy and Socio-economic Problems: A Case Study of Pakistan. National Institute of Strategic Studies (NIPS), 4, 1-5.

Aslam, F., \& Baloch, A. J. (2012). Socio-Economic Challenges in Pakistan. Retrieved from http://sujo.usindh.edu.pk/index.php/THE-GOVERNMENT/article/download/922/864

Costa, A., et al. (2014). Your Morals Depend on Language. PLOS ONE, 9(4). https://doi.org/10.1371/journal.pone.0094842

Elias, J. J. (2012). On Wings of Diesel: Trucks, Identity and Culture in Pakistan. Oxford: One World Publishers.

Gee, J. P. (2014). An Introduction to Discourse Analysis: Theory and Method. New York, USA: Routledge, Taylor, and Francis Group.

Greene, D. J. (2015). The Rise of Moral Cognition. Cognition, 135, 39-42. https://doi.org/10.1016/j.cognition.2014.11.018

Halliday, M. K. (1985). An Introduction to Functional Grammar. London: Arnold.

Halliday, M. K., \& Hasan, R. (1989). Language, Context, and Text: Aspects of language in a social-semiotic perspective. London: Oxford University Press.

Halliday, M. A., \& Hasan, R. (1976). Cohesion in English. New York: Longman.

Hare, M. R. (1952). The Language of Morals. New York: Clarendon Press.

Janks, H. (2005). Language and the Design of Texts. English Teaching: Practice and Critique, 4(3), 97-110.

Khan, A. (2013). Politically Charged Rickshaw Art. Retrieved from http://www.mantlethought.org/arts-and-culture:politically-charged-rickshaw-art

Khan, Z. (2015). Truck Drivers Deliver People, Goods - and Politics. The Express Tribune. 
Kumar, R. (2015). Wisdom on Wheels in India. Retrieved from http://binscorner.com/pages/w/wisdom-on-wheels-in-india.html

Long-Crowell, E. (2014). Social Roles: Definition and Types of Social Roles. Retrieved from http://education-portal.com/academy/lesson/social-roles-definition-and-types-of-socialroles.html\#lesson

Sahni, S. (2016). These Quirky Messages on Wheels Show That Truck Drivers Are Actually Ad Gurus in Disguise. Retrieved from https://www.scoopwhoop.com/Quirky-Messages-On-Wheels-Truck-Drivers-Ad-Gurus-In-Disguise/\#.cw5q zmazl

Swann, J., et al. (2004). A Dictionary of Sociolinguistics. Edinburgh: Edinburgh University Press.

Taluah, A. R., \& Musah, A. (2015). Moving Poetics: A Linguistic Analysis of Inscriptions on Vehicle. The Dawn Journal, 4(2), 1126-1139.

Tomasello, M., \& Vaish, A. (2013). Origins of Human Cooperation and Morality. Annual Review of Psychology, 64(1), 231-255. https://doi.org/10.1146/annurev-psych-113011-143812

Younas, R. M., et al. (2015). Social Mobility and Cultural Resource Management: Discourse Analysis. Pakistan Association of Anthropology, 27(1), 687-689.

Yule, G., \& Brown, G. (2004). Discourse Analysis. UK: Cambridge University Press.

\section{Copyrights}

Copyright for this article is retained by the author, with first publication rights granted to the journal.

This is an open-access article distributed under the terms and conditions of the Creative Commons Attribution license (http://creativecommons.org/licenses/by/4.0/). 